\title{
Social Norms Moderate the Effect of Tax System on Tax Evasion: Evidence from a Large-Scale Survey Experiment
}

\author{
Maciej A. Górecki ${ }^{1}$ Natalia Letki ${ }^{2}$
}

Received: 15 October 2018 / Accepted: 7 April 2020 / Published online: 16 April 2020

(c) The Author(s) 2020

\begin{abstract}
In this study, we reconcile conflicting findings from the extant literature on the impact of tax system parameters on tax noncompliance. We argue that social norms play a role of heuristics facilitating tax payers' response to the instrumental incentives posed by the systemic parameters, such as tax rate and penalties for evasion, and thus moderate the effect of those parameters on willingness to evade taxes. Relying on a unique survey experiment conducted in fourteen countries of CentralEastern Europe, we demonstrate two types of a conditioning effect of norms. First, the impact of tax rates on respondents' propensity for tax evasion is moderated by the perceived norms of the society at large (descriptive norms). In particular, an increasing tax rate lowers the probability of evasion as long as one views "most others" as honest taxpayers, which highlights the importance of equitability (fairness) concerns for tax compliance decisions. In contrast, the impact of punishment is moderated by the perceived norms of one's immediate reference group (subjective norms). Strong subjective compliance norms tend to effectively replace penalties as a mechanism discouraging tax evasion, suggesting that the deterrent effect of a penalty can be entirely suppressed when subjective norms are strong. These findings have important implications for the understanding of tax compliance decisions under different formal and informal regimes.
\end{abstract}

Keywords Economic behavior $\cdot$ Tax evasion $\cdot$ Social norms

\section{Introduction}

Tax (non)compliance is a topic that continues to attract interest on the part of both academics and policy-makers. This is no surprise as practical implications of tax-related behavior are indisputable and far-reaching. Despite the persistent relevance of the topic, however, the plethora of studies of the effects of systemic parameters on people's propensity to comply with tax law have thus far yielded a rather inconclusive body of evidence. For example, research focusing on a parameter as fundamental as tax rate demonstrates that its effect on the propensity to evade taxes may be positive

Maciej A. Górecki

maciej.gorecki@psych.uw.edu.pl

Natalia Letki

n.letki@uw.edu.pl

1 Faculty of Psychology, University of Warsaw, Stawki 5/7, 00-183 Warsaw, Poland

2 Faculty of Political Science and International Studies, University of Warsaw, Krakowskie Przedmieście 26/28, 00-927 Warsaw, Poland
(Alm et al. 1992; Collins and Plumlee 1991; Friedland et al. 1978; Park and Hyun 2003), negative (Alm et al. 1995), or virtually nil (Kirchler et al. 2008). Likewise, scholars are not unanimous on whether or not deterrence constitutes an effective tool preventing noncompliance. On the one hand, penalties for evasion tend to be viewed as a sine qua non condition of tax system legitimacy (Doran 2009; Kirchler et al. 2008). On the other, some scholars have pointed to their potentially detrimental effect on tax-related norms (Frey and Holler 1998, p. 28; Posner 2000, pp. 1790-1791).

The crucial contribution offered by our paper lies in reconciling the aforementioned conflicting evidence by showing that the interpretation — and thus the impact —of institutional parameters on tax evasion depends on social norms. In other words, we assume that tax payers constantly operate on the verge of formal institutions of the state, such as tax systems, and informal institutions of the society, including broadly conceived social norms. At the very general level, our approach thus builds on Vernon L. Smith's (2003) distinction between "constructivist rationality" and "ecological rationality". The former is based on top-down mechanisms driven by formally grounded instrumental incentives, while 
the latter emerges spontaneously from the bottom as a mixture of "homegrown principles of action, norms, traditions and "morality"" (Smith 2003, pp. 469-470).

We advance a number of propositions linking the effects of the systemic parameters to the strength of particular types of tax compliance norms. We argue that tax compliance is largely an outcome of context-formal and informal institutions and their interaction. More precisely, we argue that each of the two basic features of a tax system, i.e., tax rate and penalty for evasion, are interpreted by the tax payers through the lens of considerations based on social norms. In other words, different types of social norms play a role of heuristics, facilitating tax payers' decision-making processes (Gigerenzer and Todd 1999) and thereby helping them respond to the instrumental incentives posed by the systemic parameters. In accordance with the above, we argue that the impact of tax rates on people's propensity to evade taxes can be best understood framed as free-riding in the context of a large-N collective action. Thus, it strongly depends on tax payers' perception of the descriptive tax norms, that is, norms of the society at large (most usually, one's nation). Due to fairness considerations (Smith 2003; Abraham et al. 2018), an increase in tax rate may "crowd in" tax-compliant behavior, as some previous studies have suggested (see e.g., Alm et al. 1995), but only as long as one believes that "most others" are honest tax payers. Otherwise, it should "crowd out" compliance (Alm et al. 1992; Collins and Plumlee 1991; Friedland et al. 1978; Park and Hyun 2003).

When it comes to the effect of deterrence, it is best understood in the context of shaming. Thus, we claim that its effect on tax evasion depends on the subjective social norms, that is, one's perception of tax norms operating within one's immediate reference group. If those norms are perceived as not favoring compliance then the impact of a potential punishment on the propensity for evasion should be negative. By contrast, strong compliance norms of one's reference group tend to play a role of an effective substitute of prospects of punishment (e.g., Kroneberg et al. 2010). Thus, penalties should be virtually irrelevant in the case of those who see their own group as a source of such norms and, as a result, the effect of deterrence should vanish for such tax payers. In order to test the aforementioned regularities, we rely on a large-scale cross-national survey experiment conducted in fourteen countries of Central and Eastern Europe. The results largely support our conjectures.

The paper proceeds as follows. The following two sections touch upon the systemic parameters and norms as determinants of tax compliance and noncompliance. The fourth section presents the theoretical reasoning behind the proposition about social norms moderating the effects of tax rates and penalties on evasion. In particular, it explicates how the instrumental motivations elicited by tax systems interact with different types of norms in influencing the propensity for tax evasion. The fifth section describes the data we use, discusses the model to be estimated and presents the construction of the main variables relied on in the empirical analyses. The sixth section presents and discusses the results that we obtain. This is followed by a discussion of robustness checks that we conduct. The last section summarizes the paper.

\section{Tax System and Instrumental Incentives for Tax Compliance}

The classic "portfolio" approach to tax compliance assumes what Vernon L. Smith (2003) terms as "constructivist rationality", a top-down mechanism whereby formal institutions, primarily the institutions of the state, elicit instrumental incentives to comply with tax regulations. Under this framework, a decision to comply or not to comply with tax law can be thought of in terms of monetary costs and benefits (Allingham and Sandmo 1972; Alm 2012). Tax rate is thus a crucial parameter here as the amount of tax one evades when underreporting a certain amount of income is an amount of money one effectively "saves" (Thurman 1989). As higher tax rates translate into higher returns to evasion, tax payers' propensity to underreport their income in an effort to avoid being taxed should increase as tax rates grow. Allingham and Sandmo's (1972) classic analysis adds an important caveat to this line of reasoning, pointing to the possibility that under a regime of high taxes the tax payers shall be less wealthy and, hence, more risk-averse than they would be if taxes were low. This would actually suggest an increased tendency for compliance when taxes are high. The bulk of laboratory experiments on tax evasion tend to lend support to the former, more straightforward claim (Alm et al. 1992; Collins and Plumlee 1991; Friedland et al. 1978; Park and Hyun 2003). Nonetheless, evidence for the opposite (Alm et al. 1995) or no effect whatsoever (Kirchler et al. 2008) is also occasionally found. There have also been studies relying on actual tax returns, finding that higher tax rates tend to lead to greater evasion (e.g., Clotfelter 1983; Slemrod 1985). Overall, therefore, the evidence on the effect of tax rate is inconclusive (Alm 2012).

The situation is no less complex when penalties for evasion are considered, as existing literature offers numerous diverging and conflicting propositions. Starting from the most straightforward standpoint, one can interpret penalties as a mere deterrent or, more positively, as an instrument the state uses to "encourage" tax compliance. Low penalties are unlikely to serve such purposes well (Doran 2009) as they may suggest to tax payers that the state is "weak", thus undermining the overall legitimacy of the tax system (Kirchler et al. 2008). High penalties may not exert a desirable effect either, as they may be an indicator of the state's 
hostility and inconsiderateness, which might be equally harmful from the legitimacy viewpoint (Kirchler et al. 2008). In the long run, tax morale may simply be "crowded out" by both low and high penalties (Frey and Holler 1998, p. 28). Overall, empirical research has found mixed evidence about the effect of penalties: some have found no significant impact, while others have identified a logarithmic effect (Doran 2009; Ugrin and Odom 2010; Van Dijk et al. 2014).

\section{Norms as Determinants of Tax Compliance}

Apart from "constructivist rationality", Vernon L. Smith emphasizes the importance of "ecological rationality", arising spontaneously from the bottom and comprising mechanisms such as "homegrown principles of action, norms, traditions and "morality"” (Smith 2003, pp. 469-470). In the same vein, the behavioral approach to the issue of tax compliance focuses on the influence of social interactions and dynamics, in particular-tax-related norms (Pickhardt and Prinz 2014; Bobek et al. 2013). Unlike individual rationality, which is outcome-oriented, social norms are processoriented and play a distinct, yet crucial role in determining tax-related behavior (e.g., Alm 2012; Frey 1997). Norms stemming from social interaction add more nuance to the picture of human behavior dominated by the pure calculus of the narrowly defined costs and benefits. Research on the role of social norms - "rules and standards that are understood by members of a group, and that guide and/or constrain social behavior without the force of law" (Cialdini and Trost 1998, p. 152) —on tax behavior distinguishes three most fundamental types of norms. Tax payers' perceptions of the behavior of broadly conceived "others" are called descriptive norms. Subjective norms capture what the tax payer believes to be the normative expectations imposed on her by "referent others", the "referent others" being the group of people she interacts with in her everyday life (Bobek et al. 2007; Bobek et al. 2013; Cialdini and Trost 1998). Such a salient group might be limited to family members and relatives, but it might also include friends and neighbors or even members of one's occupational group (Sigala et al. 1999). Finally, the core of a tax payer's tax morale is constituted by personal norms - "self-based" standards and expectations.

While the "traditional" view in the existing literature expects subjective norms to be strongly correlated with personal norms (Wenzel 2005; Bobek et al. 2007), more recent research shows that they actually form distinct dimensions (Bobek et al. 2013). This corresponds to different ways of "acquiring" personal and subjective norms. The former are internalized convictions as to what the "right" behavior is, imprinted in the course of the socialization process and linked to other permanent social value orientations (Brizi et al. 2015). They thus should be subject to little change and show little variability over the tax payer's life course. The latter originate externally and adherence to them is motivated by conformity, that is, the desire to act in the manner accepted by one's reference group in order to avoid negative emotions such as shame and guilt. Because of its high sanctioning capacity, the reference group of the "everyday environment" is expected to be nearly as influential in shaping behavior as is people's own moral code (Mehlkop and Graeff 2010, pp. 195-196). However, unlike personal norms, subjective (and descriptive) norms can change as one's social environment changes. Qualitative research shows that different reference groups have different social norms regarding tax behavior, and that communication with family and friends increases tax compliance due to the sense of guilt (Onu and Oats 2015). Overall, there exists strong evidence for the subjective norms acting as an indicator of the shaming and sanctioning capacity of one's immediate social context.

Descriptive norms originate from one's perceptions and beliefs with respect to the behaviors dominant in the society at large, most usually operationalized as one's nation (e.g., Wenzel 2004a). ${ }^{1}$ As such, these norms seem critical when one's decision of whether or not to comply with tax regulations is being conceived of in terms of a large- $\mathrm{N}$ collective action dilemma. People's "empirical expectations" as to what (most) others do determine their perceptions of the success or failure of such a collective action (Bicchieri and Xiao 2009) as a typical (thus acceptable) or an atypical (thus unacceptable) behavior. Consequently, substantial psychic costs may be incurred to those who behave in a manner opposite to what they believe is a norm in their respective society, thereby becoming "suckers" or "leeches" (Hibbing and Alford 2004), and these costs will likely grow under a regime of high taxes. Curiously, however, previous research shows that, unlike subjective and personal norms, descriptive norms tend to have an only indirect effect on compliance (Bobek et al. 2013).

\section{Reconciling Inconclusive Evidence: Norms as Moderators of the Effects of Tax System Parameters}

The first part of the literature review above illustrates the lack of unanimous conclusions about the effect of the most fundamental features of the tax system, i.e., penalty and tax rate, on tax compliance. The second one describes the

\footnotetext{
1 We note that in some previous studies (e.g., Wenzel 2004a; Wenzel 2005) norms of the society at large are referred to as "social" rather than "descriptive" ones. Throughout this paper, however, we follow Cialdini and Trost (1998) and Bobek et al. (2013) and use the term "descriptive norms".
} 
complex web of social norms' effects on compliance. The impact of norms might, however, be of a more fundamental nature than discussed above. Namely, apart from encouraging or discouraging (directly or indirectly) tax-compliant behavior and acting independently of the formal institutions (Cialdini and Trost 1998), norms might condition people's perception of the tax system features and tax-related duties. In particular, norms may play a role of heuristics, that is, useful shortcuts facilitating decision-making processes in complex environments (see Gigerenzer and Todd 1999, pp. 31-32). They can thus help people respond to the instrumental incentives posed by formal institutions of the state. In accordance with this, we argue that the inconclusive evidence about the effect of tax system parameters, such as tax rates and penalties for evasion, on tax compliance is due to their effect being moderated by social norms. As a result, the impact of those parameters is likely to vary depending on the prevalent social norms. In particular, we emphasize the moderating effects of norms formed above the individual (personal) level, that is, subjective and descriptive norms. This is because they are more relevant from the point of view of encouraging tax compliance, as they can change to mirror the tax payer's changing perceptions of other people's norms and behavior.

To the best of our knowledge, the only research efforts to explore the possibility that such informal social context influences people's perceptions of the parameters of the tax system are the studies by Wenzel (2004b) and Coricelli et al. (2014). Wenzel (2004b) studies norm-conditioned effects of deterrence (sanctions) on people's propensity for tax compliance. He focuses on the descriptive norms, and finds that the deterrence effect of penalties is particularly pronounced under a favorable descriptive context. ${ }^{2}$ We should emphasize here that Wenzel (2004b) does not study norms of respondents' immediate reference groups (subjective norms). At the same time, he emphasizes the social costs of sanctions, such as loss of one's reputation or termination of interpersonal relationships (Wenzel 2004b, p. 551), and this sort of costs are typically imposed by reference groups rather than by large aggregates of people to which the term "descriptive norms" refers (Doran 2009, p. 135). By contrast, Coricelli et al. (2014) focus on such groups in their study of the effects of sanctions for tax evasion. They demonstrate that the effect of the disutility of being detected and denounced depends on whether the reference group stigmatizes or reintegrates the offender. The same punishment results in higher levels of reoffending if the group stigmatizes instead of reintegrating. Coricelli et al. (2014) thus do not focus on norms per se but

\footnotetext{
2 As we mentioned earlier, Wenzel (2004b) uses the term "social" to describe descriptive norms.
}

rather on particular social reactions to a penalty administered by the authorities.

We extend Wenzel's (2004b) and Coricelli et al.'s (2014) findings in at least four important ways. First, we study moderating effects of subjective AND descriptive norms on people's reaction to instrumental incentives elicited by penalties for tax evasion. This way, we aim to fill the gap in the evidence presented by Wenzel (2004b). At the same time, our explicit emphasis on norms distinguishes our approach from Coricelli et al.'s (2014) study of the impact of immediate reference groups. Second, in addition to the impact of deterrence, we explore norm-conditioned effects of tax rate on people's propensity to comply with tax law. Third, our study is placed in the context where informal institutions are at least as important as formal ones, if not more (Gërxhani 2004a, b; Williams and Horodnic 2015). This is also a context marked by a relatively high prevalence of tax evasion (Gërxhani 2004b, Torgler 2012; Raczkowski and Mróz 2018), which makes our theoretical and empirical contribution particularly relevant. Finally, we offer novel evidence on distinct paths through which subjective and descriptive norms affect tax compliance by moderating the impact of the instrumental motivations elicited by tax system parameters. We believe this constitutes an original addition to the existing body of research. These distinct paths are discussed below.

\section{Tax Rate and Descriptive Norms}

While constructing the theoretical framework applied in the ensuing empirical analyses, we acknowledge the fact that tax rates and penalties are two fundamentally different types of stimuli. Thus, even though in real life they are always concurrent, they are often analyzed separately (Clotfelter 1983; Coricelli et al. 2014; Doran 2009; Posner 2000; Wenzel 2004b). Tax rate is an easily quantifiable parameter of the tax systems and thus lends itself to judgments distinguishing between successful and unsuccessful collective actions. At the same time, the success or failure of tax contributions as a collective action can only be judged from a large-N (descriptive) perspective because public goods funded by tax revenue are, more often than not, produced on a scale surpassing the contexts of small reference groups. Moreover, the common principles in accordance with which the structure of the tax is evaluated tend to be generic and widely shared constructs, emerging at the descriptive level rather than being a property of narrower groups. Abraham et al. (2018) point to efficiency and equity as such guiding principles.

Based on the above, we argue that, as long as tax rates are considered, the principle of equity (fairness) is particularly relevant (see also Wenzel 2002; Alesina and Angeletos 2005). Whether or not a tax burden will be considered 
equitable (fair) depends on context (Abraham et al. 2018). For example, inheritance tax might be considered fair if the affected recipient is considered to be relatively affluent. In the case of young recipients, considered to be less wealthy, the exact same tax burden may be viewed as not so fair, thus making evasion more acceptable. In a similar vein, context is also formed by tax-related behavior of others and thus the principle of equity can be extended to the perceived descriptive tax norms. If one files her tax, but believes that "most others" are not honest tax payers, then she will interpret the situation as a violation of the principle of equity. As the situation brings harm to her interests, she is also going to feel being "played for a sucker" (Hibbing and Alford 2004, p. 65 ). Such a feeling shall be more intense under a regime of high taxes. This is because a larger sum of money perceived as "wasted" due to others' free-riding would result in greater psychic costs of inequity (unfairness) than would a smaller sum "lost" in comparable circumstances.

However, being "played for a sucker" is not the sole type of a worrisome situation one would like to avoid. A lack of one's contribution might also be viewed by her as inequitable. Accordingly, collective action research has demonstrated that finding oneself to be in a position of a "leech", exploiting others' contributions, may have equally detrimental consequences for one's self-esteem (Hibbing and Alford 2004, p. 65; Coricelli et al. 2014). Here, psychological costs are incurred when one fails to contribute one's fair share of tax money while being convinced that "most others" are honest tax payers. The psychological costs of the (inequitable) failure to contribute shall also be magnified when taxes are high as exploiting large contributions of honest others shall be perceived as less acceptable than exploiting smaller contributions. Therefore, the perceived presence or absence of honest tax payers significantly alters the perceived equilibrium of the tax compliance game (Erard and Feinstein 1994). Based on the above reasoning, we put forward the following hypothesis.

Hypothesis 1 Higher tax rates decrease (increase) willingness to underreport income in order to evade taxes if descriptive tax norms are perceived as promoting (not promoting) tax compliance.

\section{Deterrence and Subjective Norms}

We expect that penalties for tax evasion should incentivize people to comply with tax law in a radically different manner than it is in the case of tax rates. Suffice to say that not only does incurring a penalty for evasion usually mean a monetary loss, but it also results in a shaming of a tax offender (e.g., Posner 2000; Coricelli et al. 2014). At the same time, as Doran (2009, p. 135) points out, tax compliance and noncompliance are essentially private matters and, as such, they are not made available for public review. Being penalized for evasion thus makes one susceptible to a shaming on part of only the closest group of people, that is, those who might be in a position to acquire sufficient information on one's misdeed (Coricelli et al. 2014). We thus hypothesize that instrumental incentives elicited by penalties for tax evasion will interact with subjective norms, that is, norms of one's immediate reference group. As we mentioned above, whether or not such a moderating effect operates has not thus far been examined.

The extant literature focusing on internalized personal norms can yield insights as to a potential shape of the aforementioned moderating effect of subjective norms. In particular, recent criminological literature stresses the possibility that the effect of penalties on the probability of committing a criminal act is pronounced only if moral norms do not promote compliant behavior. Most notably, Kroneberg et al. (2010) propose a correction of rational choice theories of crime causation (e.g., Matsueda et al. 2006). They argue that instrumentally rational behavior will characterize only those who are not normatively discouraged from committing crimes. ${ }^{3}$ In such cases, credible prospects of punishment will be indispensable to assure compliance with the law. In cases of strong informal control, on the contrary, the propensity to obey the law will be strong even in the absence of deterrence and the prospects of punishment will be virtually irrelevant. We argue here that members of reference groups committed to tax compliance will obey the law because of conformity (Mehlkop and Graeff, pp. 195-196) and the tendency to imitate the expected behavior of referent others (Gigerenzer and Todd 1999, pp. 31-32) rather than out of fear of punishment. In other words, subjective norms prescribing law-abiding behavior will tend to replace punishment as a factor increasing people's propensity to comply with the law, including tax regulations. Hence the following hypothesis.

Hypothesis 2 Subjective tax norms moderate the effect of penalties on tax evasion in such a way that the effect of penalty (versus no penalty) on tax evasion is strongly negative when norms are seen as not promoting tax compliance, but tends towards zero when norms are seen as promoting taxcompliant behavior.

Having said the above, we do not lose out of sight the aforementioned fact that, studying the effect of penalties

\footnotetext{
${ }^{3}$ Such an interpretation of the role of norms in conditioning the effects of instrumental incentives is not limited to crime causation mechanisms. A strikingly similar reasoning was recently proposed by Blais and Achen (2019) with respect to civic duty and its moderating effect on the processes whereby instrumental incentives affect electoral participation.
} 
Table 1 Factorial design wording

Please imagine the following situation. You have agreed to take on an extra job, and you are paid in cash for it. This income should be taxed at (a) (b)

(a)
1. $10 \%$
2. $15 \%$
3. $20 \%$
4. $25 \%$
5. $30 \%$
6. $35 \%$

(b)

1. - -

2. If it is discovered that you have not declared this income to the Tax Office, you will have to pay the amount of tax you owe and an additional penalty of $50 \%$ of this amount

3. If it is discovered that you have not declared this income to the Tax Office, you will have to pay the amount of tax you owe and an additional penalty of $100 \%$ of this amount

4. If it is discovered that you have not declared this income to the Tax Office, you will have to pay the amount of tax you owe and an additional penalty of $150 \%$ of this amount

5. If it is discovered that you have not declared this income to the Tax Office, you will have to pay the amount of tax you owe and an additional penalty of $200 \%$ of this amount

How likely it is that you will not declare this income to the Tax Office?
1. Very likely
2. Fairly likely
3. Not very likely
4. Not likely at all
(998 Don’t know)
(999 Refusal)

on tax evasion, Wenzel (2004b) actually found a moderating effect of descriptive rather than subjective norms. In addition, that moderating effect was opposite to what we proposed above with respect to the moderating effect of subjective norms, strong compliance (descriptive) norms magnifying rather than suppressing the effect of legal sanctions. The empirical analyses that follow are thus designed in such a way as to allow an evaluation of Wenzel's core hypothesis.

\section{Norm-conditioned Impact of Tax System Parameters on Tax Compliance and Noncompliance: Methods}

In this study, we analyze data collected in the course of the "Public Goods through Private Eyes" project (Letki 2015). The project's main output has been a face-to-face survey administered to nationally representative samples in fourteen Central and Eastern European countries: Bulgaria, Croatia, Czech Republic, Estonia, Hungary, Latvia, Lithuania, Moldova, Poland, Romania, Serbia, Slovakia, Slovenia and
Ukraine. ${ }^{4}$ Respondents to the survey-around 1,500 in each country-were asked about a broad range of issues related to their attitudes toward public goods and the state. A more detailed description of the survey is included in the Appendix (Tables 4, 5 and 7).

A separate section of the survey was devoted to taxrelated attitudes and behavior. Among others, a factorial design (or a vignette experiment, see Rossi 1979) was included whereby the respondents were asked to imagine a situation in which they undertake an extra job, being paid for that in cash. Factorial design has been used in social sciences (most often, in sociology) since the 1970s and it has become a useful measurement tool (Wallander 2009). Under such a design, respondents are confronted with scenarios that offer a discrete number of attributes (factors), and they are asked to indicate their opinion in the context of a given setup. Because the values of vignette factors are assigned randomly, factorial design is an experimental setup. In multivariate regression analyses, the opinion elicited is treated as a dependent variable, while factors are treated as independent variables.

\footnotetext{
${ }^{4}$ In the analyses that follow, we use appropriate weights to ensure representativeness for the entire region under study. Details of the sampling, response rates and fieldwork are provided in the Appendix.
} 
Table 2 Personal, subjective and descriptive norms and retributive justice—factor analysis (Varimax rotation), $N=14,703$

Personal norms Subjective norms Descriptive norms Retributive efficacy

Please tell me to what extent do you agree or disagree with each

of the following statements:

Paying taxes for me is an obvious thing to do $\quad 0.719$

I consider paying taxes to be my civic duty $\quad 0.755$

Paying taxes for me is a natural thing to do $\quad 0.775$

Ratings ranged from 1 (strongly disagree) to 5 (strongly agree)

Please, think about three adults you know best, like your close friends or family members. What would they think if they learnt that...

You did not declare all of your income to the Tax Office? (recoded)

You claimed more tax deductions than you were entitled to?

0.887 (recoded)

You worked for cash in payments and not paid tax on this income? (recoded)

Ratings ranged from 0 (They'd find it completely unacceptable) to 10 (They'd think there is nothing wrong with it)

Do you think...

Most people in [country] always declare all their income to the Tax Office?

Most people in [country] who work for cash-in-hand payments PAY TAXES on this income?

Ratings ranged from 0 (strongly disagree) to 5 (strongly agree)

Now, I would like to ask you some questions related to how law works in our country. Using this card tell me to what extent do you agree or disagree with the following statements:

One can be sure that in [country] people who break the law will

get punished

In this country law is applied to everyone equally

Ratings ranged from 0 (strongly disagree) to 5 (strongly agree)

Mean (for the version of variables ranging from 0 to 1 )

0.776

(0.199)

(SD)

Sample-level pairwise correlations ( $\mathrm{p}$ value)

Subjective norms

Descriptive norms

Retributive efficacy

$* * * p<0.001$

When designing the vignette, we followed in the footsteps of Thurman (1989), but details such as the number of variable parameters as well as their operationalization in our experiment differ substantially from the version implemented by that author. The parameters of the tax system, that is, tax rate and the severity of penalty, were assigned randomly to respondents. In the end, respondents were asked to rate how likely it is that they will not declare the extra income. Full vignette wording is presented in Table 1, while the distribution of vignette factors and responses is presented in Table 5 in the Appendix.

Having said the above, we build our model based on the following variables derived from the vignette question:

EVASION-an ordinal four-point (i.e., 1-4) tax evasion scale based on the aforementioned vignette question and taking higher values as respondents' propensity to underreport the extra income, and thus evade being taxed, increases.

RATIO - the rate at which the hypothetical income would be taxed (if declared), randomly assigned to the respondents in the vignette question, divided by the tax rate in a respondent's country. The original variable takes the following six values: $10 \%, 15 \%, 20 \%, 25 \%, 30 \%$ and $35 \%$. To take into account that these values may have different meaning depending on the tax rate that applies to the respondents in their real-life settings, we recoded the original values as the ratio of the vignette factor value to the income tax level in the respondent's country. We took the income tax rates for the year of the survey, and for the progressive tax system countries we took the lowest (basic) level of income tax as a benchmark. The ratio of the vignette factor value to the respondent's tax ranges from 0.385 to 5 , and the sample 
mean is equal to $1.583(\mathrm{SD}=0.875)$. This variable was then recoded so that it ranges from 0 to 1 , with a mean of 0.260 $(\mathrm{SD}=0.190)$. The reason for this second step of variable transformation was to make the interpretation of regression coefficients of variables with different scales more straightforward, especially in the presence of interaction effects.

PENALTY - a binary variable indicating whether or not the possibility of being penalized if caught underreporting an extra income was mentioned to a respondent. In the original vignette question, one of five different scenarios was randomly assigned to each respondent. No mention of a penalty was made to a group of respondents while four other groups received a mention of a penalty equal to the amount owed plus, respectively, 50\%, 100\%, 150\% and 200 cent of underpaid tax. Preliminary analyses demonstrated that the differences between effects of different levels of penalty were not statistically significant, with the only substantial difference in the propensity to underreport an extra income being between the first category of respondents (no mention of a penalty) and all others. ${ }^{5}$ We have thus decided to simplify our analyses by focusing on the aforementioned binary penalty variable.

Other survey questions, crucial for the concepts advanced here, explored respondents' perceptions of (social) tax norms. To identify different levels of norms, we have resorted to factor analysis. Previous research emphasized one-dimensionality of tax norms, with a particularly strong correlation between personal norms and those of one's closest reference group (Bobek et al. 2007; Wenzel 2005). We have employed eight different items capturing respondents' views of their own and others' commitment to paying taxes. Factor analysis detected three distinct dimensions. Factor loadings, means and standard deviations, as well as correlations between norms dimensions are presented in Table $2 .{ }^{6}$

We have constructed the following three variables capturing, respectively, personal, subjective and descriptive norms.

PERSONAL is an index capturing the strength of internalized personal tax compliance norms. It is based on a respondent's position on three statements: "Paying taxes is for me an obvious thing to do", "I consider paying taxes

\footnotetext{
${ }^{5}$ Results available from the authors on request.

${ }^{6}$ These exploratory factor analysis results were further tested by applying a confirmatory factory analysis to the dimensions identified. While the model $\chi^{2}$ test produces a coefficient of $114.34(\mathrm{df}=17)$ and significant at $p<0.001$, which indicates that our model has a worse fit to the data than the saturated model, $\chi^{2}$ is strongly affected by the sample size, which in our case is a rather large $N=14,093$. Other indices indicate a very good fit: the model's comparative fit index (CFI) of 0.998 exceeds the recommended cut-off point of 0.90 , and so does the Tucker-Lewis Index (TLI) of 0.997, and the root mean square error of approximation (RMSEA) of 0.020 is below the recommended threshold of 0.08 . The results of the analysis are available from the authors on request.
}

to be my civic duty" and "Paying taxes is for me a natural thing to do", expressed on an ordinal scale from 1 (strongly disagree) to 5 (strongly agree), with "Don't know" answers recoded to the middle of the scale (value 3 ). The final variable is an average of the three items, recoded in such a way as to increase as personal norms (promoting compliance) become stronger and to take the values between 0 and 1 . Even though we do not propose any specific hypotheses for the effect of personal tax norms, we nonetheless include them in the models in order to ensure that the detected effect of SUBJECTIVE and DESCRIPTIVE norms is not partly capturing the effect of personal norms.

SUBJECTIVE is the index capturing the strength of subjective tax compliance norms, that is, the norms of a respondent's reference group. This variable measures an expected judgment by three adults a respondents knows best, such as family members or close friends, of two hypothetical situations: the respondent's not declaring all of her income to tax authorities and the respondent's working for (not declared) cash-in-hand payments. The original variables were measured on an ordinal scale ranging from 0 (They'd find it completely unacceptable) to 10 (They'd think there is nothing wrong with it) with the "Don't know" answers recoded to the middle of the scale (value 5). The final variable is an average of the two items, recoded in such a way as to increase as subjective norms (promoting compliance) become stronger and to take the values between 0 and 1 .

DESCRIPTIVE refers to the strength of descriptive tax norms. It measures respondents' perceptions of the tax behavior of fellow citizens: "Most people in your country always declare all their income to the Tax Office" and "Most people in your country who work for cash-in-hand payments pay taxes on this income". The answers ranged from 0 (strongly disagree) to 5 (strongly agree), with "Don't know" answers recoded to the middle of the scale (value 3 ). The final variable is an average of the two items, recoded in such a way as to take the values between 0 and 1 .

Table 2 contains means and SDs of the three norms measures. They show that respondents present themselves as having strong pro-compliance norms, their immediate social environment as being fairly lenient on noncompliance (around the middle of the scale), and they rather disagree that most people in their country are honest tax payers. Interestingly, the bivariate correlations between these three constructs are weak, even if all but one highly statistically significant. Due to the sample size, the statistical significance is no surprise, however.

Research on the determinants of tax evasion tends to follow the Allingham and Sandmo's (1972) classic analysis, in which a prominent role is played by the tax payer's perceived probability of detection. Although this is not central to our argument, we nonetheless believe that controlling for respondents' perceptions of the retributive capabilities 
of legal institutions in their respective country is necessary. ${ }^{7}$ In order to do so, we include in our model a variable RETRIBUTIVE-an index based on two survey items: "One can be sure that in [country] people who break the law will get punished" and "In this country law is applied to everyone equally". The answers were on a scale ranging from 0 (strongly disagree) to 5 (strongly agree), with "Don't know" answers recoded to the middle of the scale (value 3). Subjected to factor analysis along norms items, these two questions formed a separate dimension (see Table 2). The final variable is an average of the two items, recoded in such a way as to increase as the system's retributive capacity is evaluated higher, and to take the values between 0 and 1 .

We further control for a range of standard socio-economic characteristics. These variables include: AGE (a respondent's age in years), FEMALE (a binary variable taking the value of 1 if a respondent is a woman and the value of 0 if a respondent is a man), DEGREE (a variable indicating whether or not a respondent has completed university education) and WORKING (a binary variable taking the value of 1 if a respondent is part- or full-time employed at the time of the interview and the value of 0 otherwise). Given that our design is experimental, it is not necessary to control for the socio-economic status. At the same time, because the PERSONAL norms questions were asked only to those respondents who have ever paid taxes, the effective sample is reduced. It is thus representative of the population of those who have ever been due to pay taxes, rather than to the entire population. To make sure that the aforementioned sample reduction does not affect the results, we control for the basic socio-economic background characteristics. All the analyses that follow have been repeated with and without socio-economic controls and the results are virtually identical no matter whether socio-economic characteristics are controlled for or not.

Given all the aforementioned variables, we propose the following model explaining the propensity for tax evasionthat is, not declaring an extra income paid in cash-for the $i$ th respondent in the $j$ th country:

(1) $\operatorname{Pr}\left(\right.$ EVASION $\left._{\mathrm{ij}}=\mathrm{p}\right) \sim \beta_{0}+\beta_{1}$ RATIO $_{\mathrm{ij}}+\beta_{2}$ PENALTY $_{\mathrm{ij}}$ $+\beta_{3}$ SUBJECTIVE $_{\mathrm{ij}}+\beta_{4}\left(\right.$ RATIO $_{\mathrm{ij}} \times$ SUBJECTIVE $\left._{\mathrm{ij}}\right)$ $+\beta_{5}\left(\right.$ PENALTY $_{\mathrm{ij}} \times$ SUBJECTIVE $\left._{\mathrm{ij}}\right)+\beta_{6}$ DESCRIPTI VE $_{\mathrm{ij}}+\beta_{7}\left(\right.$ RATIO $_{\mathrm{ij}} \times$ DESCRIPTIVE $\left._{\mathrm{ij}}\right)+\beta_{8}\left(\right.$ PENALTY $_{\mathrm{ij}}$ $\times$ DESCRIPTIVE $\left._{\mathrm{ij}}\right)+\beta_{9}$ PERSONAL $_{\mathrm{ij}}+\beta_{10}$ RETRIB UTIVE $_{\mathrm{ij}}+\beta_{11} \mathrm{AGE}_{\mathrm{ij}}+\beta_{12}$ FEMALE $_{\mathrm{ij}}+\beta_{13}$ DEGREE $_{\mathrm{ij}}$ $+\beta_{14}$ WORKING $_{\mathrm{ij}}+\varepsilon_{\mathrm{ij}}+\psi_{\mathrm{j}}$

\footnotetext{
7 In Thurman (1989), retributive justice was assessed by a factor referring to the probability of an audit.
}

where the variables (written in capital letters) are those described above and, in addition:

- $p$ is a point on an ordinal scale of tax evasion (1-4),

- $\varepsilon_{i j}$ is respondent-level residual term,

- $\psi_{j}$ is country fixed-effect.

The variety of our data and the diversity of societies covered by our survey warrant a few important remarks. Namely, while emphasizing general abstract regularities, we also account for the specificity of the fourteen countries we study, especially in terms of the cross-country differences with respect to tax systems. We do so in three ways. First, as mentioned above, our operationalization of tax rate is a ratio of the experimentally induced tax rate to the actual tax rate in a respective country. This accounts for the rather substantial cross-country differences in tax rates. Second, we re-estimate our model separately for countries implementing a flat tax rate and those with a progressive tax. Finally, as formula (1) indicates, we account for other potentially unobserved country-specific factors, such as the cultural or political heterogeneity, by including country-specific fixedeffects in our model.

Before proceeding to the analyses, two further remarks on our estimation strategy are necessary. First, we include interactions of both tax rate (RATIO) and sanctions (PENALTY) with subjective and descriptive norms. We proposed that tax rate and penalty are interpreted by tax payers through a different lens, with the former being affected by fairness considerations in the context of large- $\mathrm{N}$ collective action, and the latter being dependent on the shaming capacity of the tax payer's immediate social context. The interactions are included to demonstrate the way norms moderate the impact of tax system parameters on the propensity for evasion and thereby test hypotheses 1 and 2 (see above). Obviously, in order to test those hypotheses one would require examining only interaction effects between RATIO and DESCRIPTIVE as well as between PENALTY and SUBJECTIVE. We nonetheless test also for the presence of the two other possible interaction effects, that is, between RATIO and SUBJECTIVE as well as between PENALTY and DESCRIPTIVE, the latter constituting a test of Wenzel's (2004b) core hypothesis). This will help us to establish if the moderating effects of norms are confined to what we proposed above, thus enhancing the credibility of our theoretical argument.

Second, as indicated earlier, we do not include in our main model the interactions of the two parameters of the tax system with personal norms (PERSONAL). Personal norms are less essential for the concepts advanced here. Nonetheless, we acknowledge the fact that those norms themselves constitute a potentially strong predictor of tax compliance and thus include them as a control variable. 
Table 3 Predictors of respondents' propensity for tax evasion: Ordinal logistic regression estimates

\begin{tabular}{|c|c|c|c|c|}
\hline Variables & $\begin{array}{l}\text { (1) } \\
\text { Baseline model }\end{array}$ & $\begin{array}{l}(2) \\
\text { Main model }\end{array}$ & $\begin{array}{l}(3) \\
\text { Flat tax rate countries }\end{array}$ & $\begin{array}{l}\text { (4) } \\
\text { Progressive } \\
\text { tax rate coun- } \\
\text { tries }\end{array}$ \\
\hline Tax (as ratio) & $\begin{array}{l}-0.457^{*} \\
(0.245)\end{array}$ & $\begin{array}{l}0.972 * * \\
(0.489)\end{array}$ & $\begin{array}{l}1.496 * * \\
(0.688)\end{array}$ & $\begin{array}{l}0.005 \\
(0.668)\end{array}$ \\
\hline Penalty & $\begin{array}{l}-0.306^{* * * *} \\
(0.073)\end{array}$ & $\begin{array}{l}-0.692 * * * \\
(0.182)\end{array}$ & $\begin{array}{l}-0.684 * * * \\
(0.205)\end{array}$ & $\begin{array}{l}-0.662 * * \\
(0.322)\end{array}$ \\
\hline Subjective & $\begin{array}{l}-1.130 * * * \\
(0.110)\end{array}$ & $\begin{array}{l}-1.359 * * * \\
(0.286)\end{array}$ & $\begin{array}{l}-1.365^{* * *} \\
(0.339)\end{array}$ & $\begin{array}{l}-1.487 * * * \\
(0.508)\end{array}$ \\
\hline Subjective $\times$ tax rate & & $\begin{array}{l}-1.244 * * \\
(0.593)\end{array}$ & $\begin{array}{l}-0.917 \\
(0.905)\end{array}$ & $\begin{array}{l}-1.201 \\
(0.780)\end{array}$ \\
\hline Subjective $\times$ penalty & & $\begin{array}{l}0.623 * * \\
(0.250)\end{array}$ & $\begin{array}{l}0.595 * * \\
(0.283)\end{array}$ & $\begin{array}{l}0.749 \\
(0.456)\end{array}$ \\
\hline Descriptive & $\begin{array}{l}0.0784 \\
(0.160)\end{array}$ & $\begin{array}{l}0.371 \\
(0.437)\end{array}$ & $\begin{array}{l}0.659 \\
(0.520)\end{array}$ & $\begin{array}{l}0.118 \\
(0.817)\end{array}$ \\
\hline Descriptive $\times$ tax rate & & $\begin{array}{l}-2.380 * * \\
(0.939)\end{array}$ & $\begin{array}{l}-3.706 * * * \\
(1.349)\end{array}$ & $\begin{array}{l}-0.465 \\
(1.324)\end{array}$ \\
\hline Descriptive $\times$ penalty & & $\begin{array}{l}0.298 \\
(0.380)\end{array}$ & $\begin{array}{l}0.444 \\
(0.445)\end{array}$ & $\begin{array}{l}-0.306 \\
(0.707)\end{array}$ \\
\hline Personal & $\begin{array}{l}-0.876^{* * *} \\
(0.170)\end{array}$ & $\begin{array}{l}-0.863^{* * *} \\
(0.168)\end{array}$ & $\begin{array}{l}-0.694 * * * \\
(0.195)\end{array}$ & $\begin{array}{l}-1.205^{* * *} \\
(0.305)\end{array}$ \\
\hline Retributive & $\begin{array}{l}0.047 \\
(0.147)\end{array}$ & $\begin{array}{l}0.039 \\
(0.146)\end{array}$ & $\begin{array}{l}0.050 \\
(0.182)\end{array}$ & $\begin{array}{l}-0.002 \\
(0.240)\end{array}$ \\
\hline /cut1 & $\begin{array}{l}-2.940 * * * \\
(0.227)\end{array}$ & $\begin{array}{l}-2.936^{* * *} \\
(0.278)\end{array}$ & $\begin{array}{l}-2.557 * * * \\
(0.342)\end{array}$ & $\begin{array}{l}-3.497 * * * \\
(0.450)\end{array}$ \\
\hline /cut2 & $\begin{array}{l}-1.542 * * * \\
(0.223)\end{array}$ & $\begin{array}{l}-1.533^{* * *} \\
(0.274)\end{array}$ & $\begin{array}{l}-1.200^{* * *} \\
(0.337)\end{array}$ & $\begin{array}{l}-2.005^{* * *} \\
(0.444)\end{array}$ \\
\hline /cut3 & $\begin{array}{l}-0.243 \\
(0.221)\end{array}$ & $\begin{array}{l}-0.228 \\
(0.272)\end{array}$ & $\begin{array}{l}0.172 \\
(0.336)\end{array}$ & $\begin{array}{l}-0.798^{*} \\
(0.438)\end{array}$ \\
\hline Log pseudolikelihood & $-15,259.645$ & $-15,226.178$ & -9484.757 & -5702.663 \\
\hline Observations & 11,861 & 11,861 & 7188 & 4673 \\
\hline
\end{tabular}

All models controlled for age, sex, education (degree), whether respondent is employed. All models include country fixed-effects

Flat tax rate countries: Bulgaria, Czech Republic, Estonia, Hungary, Latvia, Lithuania, Romania, Slovakia, Ukraine. Progressive tax rate countries: Croatia, Moldova, Poland, Serbia, Slovenia

${ }^{* * *} p<0.01, * * p<0.05, * p<0.1$. Main entries are unstandardized regression coefficients and the numbers in round brackets are robust standard errors

\section{Results and Discussion}

As our dependent variable, the propensity to underreport an extra income, is measured on an ordinal scale, we model it using ordinal logistic regression. Table 3 below presents our estimates. ${ }^{8}$ The analyses that follow focus on the baseline

\footnotetext{
8 The analysis is restricted to respondents who have ever paid taxes and thus the number of observations included is substantially smaller than the overall sample size. A similar approach was recently adopted by Ferrer-i-Carbonell and Gërxhani (2016) who used the same dataset. In fact, due to some tax-related questions having been asked only to the aforementioned subsample of respondents, we were effectively forced to limit our analysis to that subsample.
}

model (model 1), that is, a model without interaction terms, and the model presented in formula (1) above (model 2). Before we proceed to discussing our results, we should note that the effects from an ordinal logistic regression model are interpreted as changes in probabilities. In this particular case, these are probabilities of the propensity to underreport an extra income reaching a certain value on the 1-4 scale. In the discussion to follow, we always refer to the change in the probability of the propensity to attempt to evade taxes reaching the lowest level (i.e., 1) or the highest one (i.e., 4).

Model 1 immediately suggests a potentially counterintuitive finding, illustrated graphically in Fig. 1. Namely, the effect of tax rate on a respondent's propensity for evasion 
Fig. 1 Effects of vignette parameters on respondents' propensity for tax evasion
Fig. 2 Effects of norms on respondents' propensity for tax evasion
Panel A. Effects on probability of respondent choosing 'not likely at all' answer

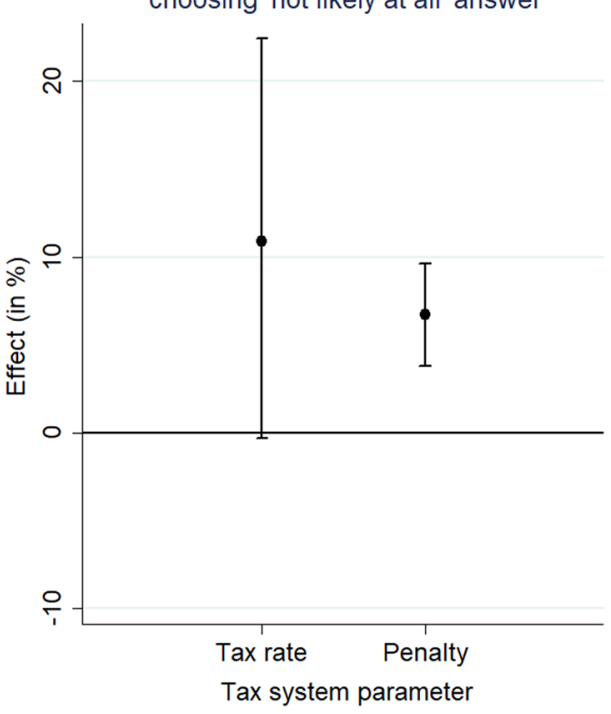

Panel A. Effects on probability of respondent choosing 'not likely at all' answer

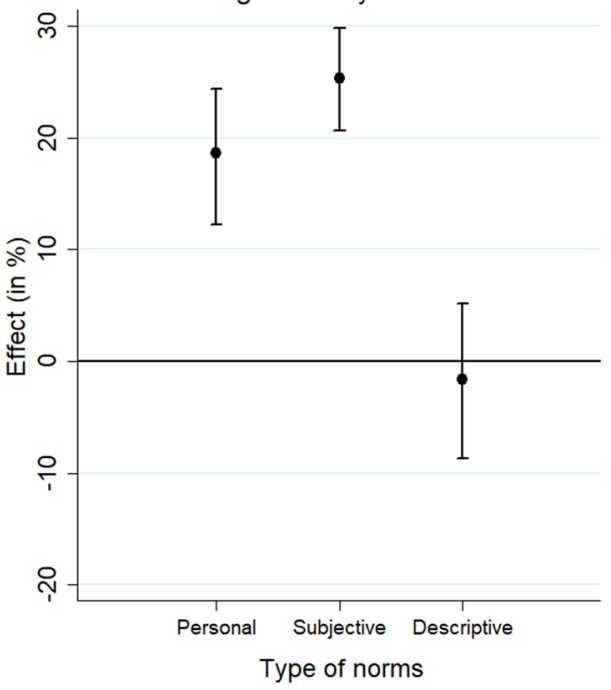

Panel B. Effects on probability of respondent choosing 'very likely' answer

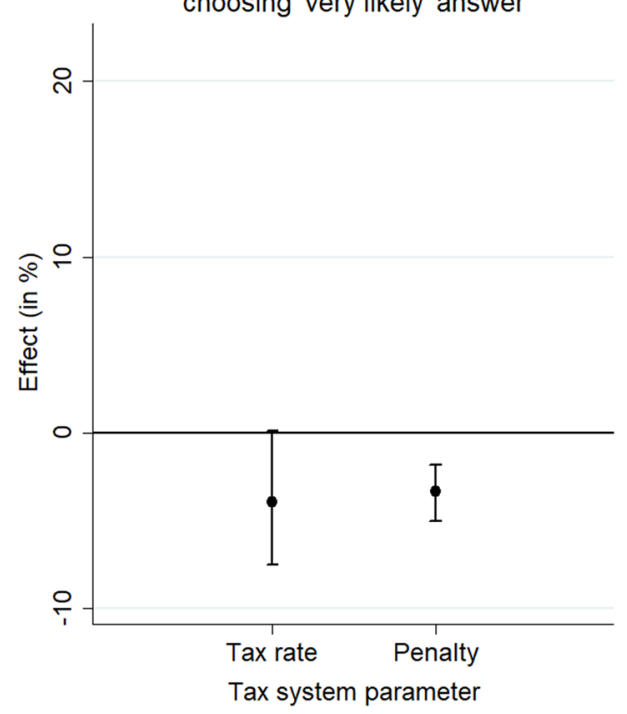

Panel B. Effects on probability of reposndent choosing 'very likely' answer

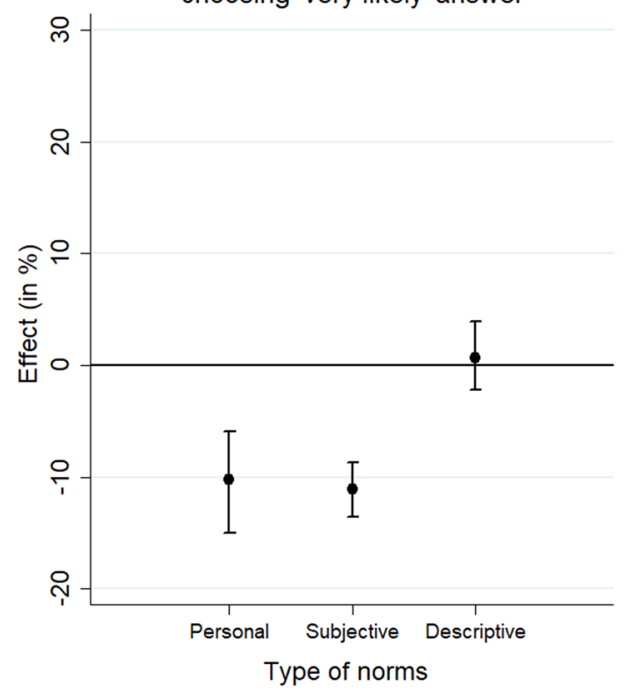

is negative, albeit marginally statistically insignificant ( $p=0.06$ ). Holding other variables constant at their medians, an increase in tax rate (RATIO) from its minimum to maximum (that is, from 0.385 of the respondents' tax rate to five times their tax rate) results in a $3.9 \%$ points decrease of the probability of the respondents declaring it 'very likely' that they would not report extra income. The exact same change in tax rate leads to a $10.9 \%$ points increase in the probability of the respondents declaring it 'not likely at all' that they would fail to declare their income to the Tax Office. ${ }^{9}$ The result that an increase in tax rate lowers propensity to evade taxes, even if somewhat surprising, is consistent with some

\footnotetext{
9 All effects and the accompanying 95\% confidence intervals were
} calculated using CLARIFY simulations software (King et al. 2000). earlier studies, most notably Allingham and Sandmo (1972) and Alm et al. (1995). The effect of a penalty for evasion is in line with intuitive expectations. Holding other variables constant at their medians, the presence of a penalty lowers the probability of the respondents declaring it 'very likely' that they would fail to declare their income by about $3.3 \%$ points. By analogy, the probability that they would declare it 'not likely at all' increases by $6.7 \%$ points. Both these effects are highly statistically significant $(p<0.01)$.

Figure 2 illustrates graphically the impact of various types of norms on a respondent's probability to underreport an extra income, based on Model 1. Consistently with previous research, personal and subjective norms seem to exert a strong influence on respondents' propensity for evasion. An increase of compliance norms from a minimum to a maximum level, 
Fig. 3 Norm-conditioned effects of tax rate on respondents' propensity for tax evasion
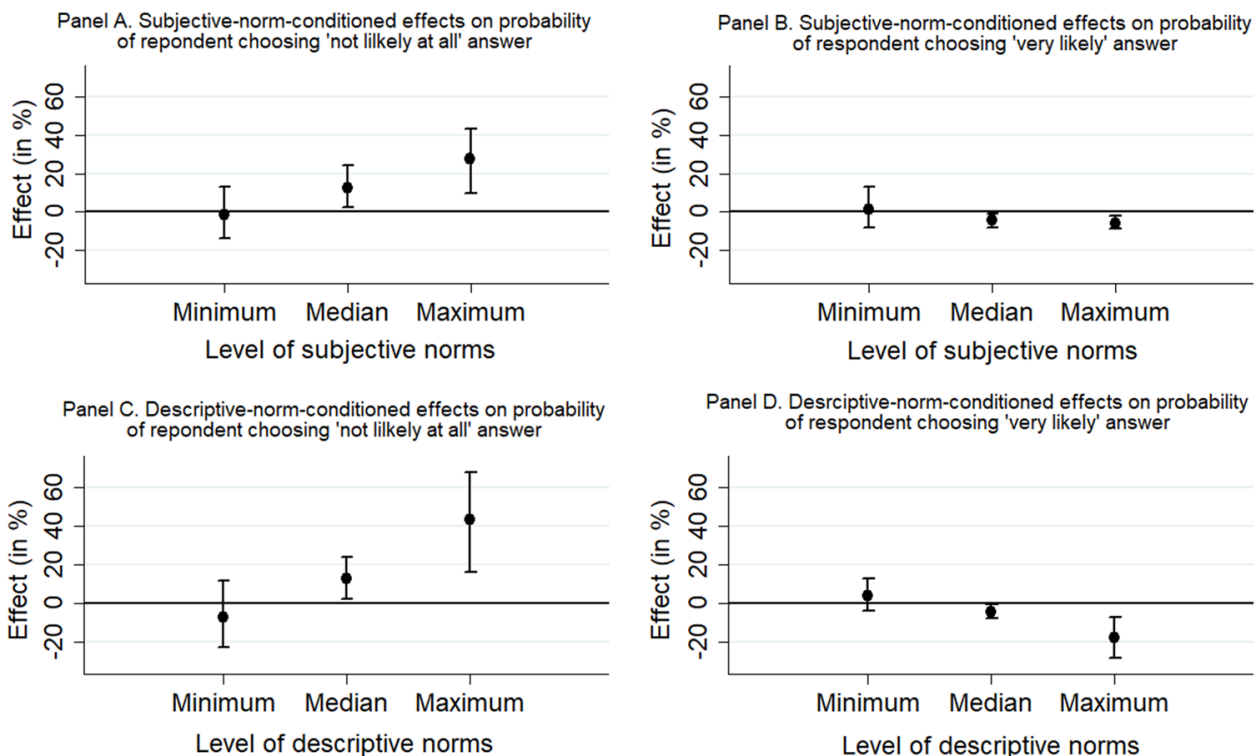

holding other variables constant, is associated with a decrease in the probability of respondents declaring it 'very likely' that they would not declare extra income by about 10.2 and about $11.1 \%$ points for personal and subjective norms, respectively. The corresponding increase in the probability of respondents declaring it 'not likely at all' that they would fail to report extra income is equal to 18.6 and $25.3 \%$ points for personal and subjective norms, respectively. All those effects are highly statistically significant. By contrast, the analogous effects for descriptive norms are weak and statistically insignificant, the respective $95 \%$ confidence intervals encompassing zero. This is also consistent with previous research that identified no direct effect of descriptive norms on compliance (e.g., Bobek et al. 2013). We thus see clearly that the source of tax-relevant norms - that is, norms that exert a strong direct effect on the propensity for compliance and noncompliance-is located in the personal domain and in the domain of respondents' closest reference groups rather than at the level of the society at large. The observed lack of direct influence of descriptive norms on tax compliance and noncompliance is likely to be a result of the fact that one's tax-related behavior is essentially "invisible" to other people (Doran 2009, p. 135). This, however, does not preclude a situation where descriptive norms moderate the effects of the parameters of the tax system on the propensity to evade, because the perceived presence of honest tax payers significantly alters the equilibrium of the "tax game" (Erard and Feinstein 1994).

As attempts to assess interaction effects in nonlinear models might lead to invalid conclusions (see e.g., Ai and Norton 2003), our analysis of the estimates obtained for model 2 is based solely on marginal effects. The results with respect to normconditioned effects of tax rates on respondents' propensity to underreport an extra income are presented graphically in Fig. 3. We have not proposed hypotheses for the moderating effect of subjective norms on tax rate, and despite the seemingly significant effect in model 2, the analysis of marginal effects shows that there is no statistically significant moderating effect here, as all the $95 \%$ confidence intervals, accompanying the respective effects for varying strength of subjective norms, overlap easily. When it comes to descriptive norms, the effects lend partial support to hypothesis 1 . When descriptive norms are weak, i.e., they represent the belief that most other people are not honest tax payers, rising tax rate increases respondents' propensity for evasion - which is in line with hypothesis 1-but this effect is relatively weak and statistically insignificant $(p>0.05)$. When descriptive norms are at their maximum level, i.e., they represent the view that most other people are honest tax payers, rising tax rate lowers the propensity for underreporting an extra income, and this effect is strong and highly statistically significant $(p<0.01)$. Holding other variables constant at their medians and descriptive norms at their maximum, an increase in tax rate from the minimum to the maximum level is associated with a decline in the probability of the respondents declaring it 'very likely' that they would not report extra income by approximately $17.9 \%$ points, an undoubtedly strong effect. The corresponding increase in the probability of them declaring it 'not likely at all' amounts to an impressive $43.4 \%$ points.

Substantively, the results taken together suggest that respondents' declared behavior is driven predominantly by a desire to avoid an inequitable situation (Abraham et al. 2018) in which one fails to contribute her fair share of tax and thereby unfairly benefits from relatively large honest contributions made by others. We observe a clear asymmetry, as_-using Hibbing and Alford's terms (2004, p. 65)—being a "leech" tends to result in greater psychic costs and is thus avoided more strongly than is the prospect of "being played for a sucker" (see also Erard and Feinstein 1994). We can also observe how the perception of tax rate shifts depending 
Fig. 4 Norm-conditioned effects of penalty on respondents' propensity for tax evasion
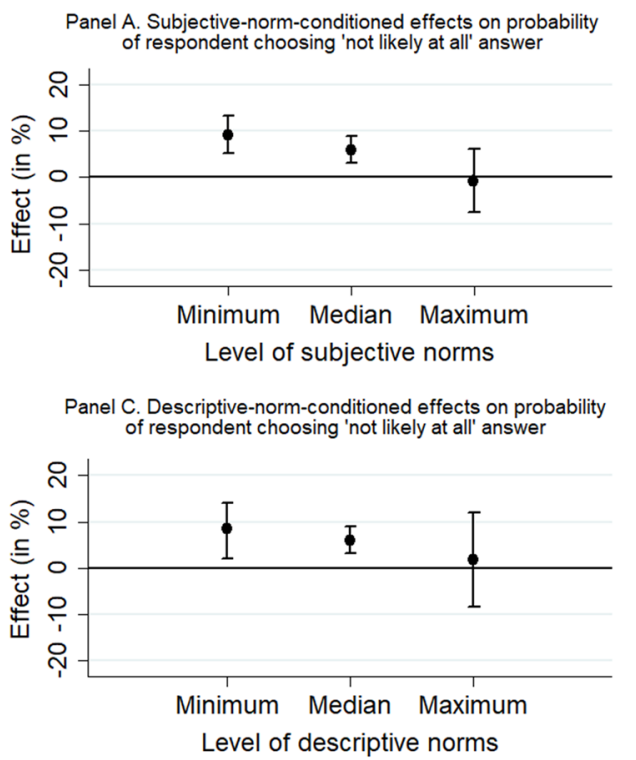

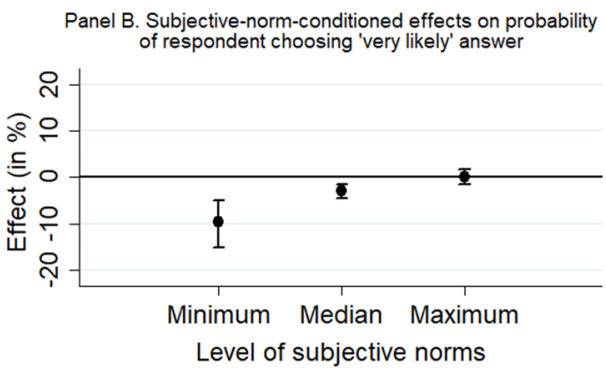

Panel D. Descriptive-norm-conditioned effects on probability of respondent choosing 'very likely' answer

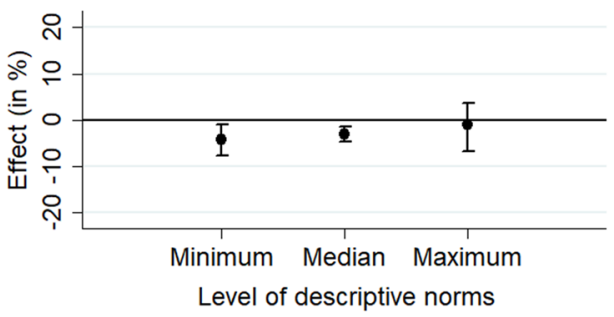

on descriptive tax norms. Increasing tax rates activate the relevance of descriptive norms; the prospects of inequity, emerging as a result of a comparison of one's behavior with the (perceived) behavior of "most others", tend to exert a noticeably strong effect only as tax rate becomes high. In the light of these results, we can therefore gain a more profound understanding of the aforementioned negative average effect of tax rate on the propensity for evasion (see Fig. 1 above). Clearly, this negative effect is driven mostly by those respondents who believe that "most others" are honest tax payers. These results, combined with the lack of moderating effect of subjective norms, indicate that the process of shaping of the respondents' perceptions of tax rates occurs predominantly through perceptions of others in the society as honest tax payers.

Norm-conditioned effects of a penalty for evasion are presented graphically in Fig. 4. As hypothesized, there is a clear-cut moderating effect of subjective norms. If tax-related norms of a respondent's immediate reference group are weak, i.e., tax evasion is seen as something acceptable, then the mention of a penalty, other things being equal, reduces the probability of the respondent declaring it 'very likely' that they would not report extra income to the Tax Office by about $9.7 \%$ points $(p<0.01)$. The effect becomes much weaker as the strength of norms reaches the median level (a decline in the propensity for evasion by approximately $2.9 \%$ points), to fade away completely for the respondents scoring highest on subjective norms, that is, when they believe their reference group considers tax evasion as something unacceptable. It is also worth emphasizing here that the respective $95 \%$ confidence interval, accompanying the effect of a penalty for respondents whose subjective compliance norms are weak, does not overlap with the corresponding $95 \%$ confidence intervals for those for whom those norms reach the median or the maximum level. The evidence presented here can thus be considered relatively convincing in statistical terms. It is so especially as the corresponding increase in the probability of the respondent declaring it 'not likely at all' that they would fail to declare extra income to the Tax Office follows the exact same norms-conditioned pattern, even if being accompanied by marginally overlapping $95 \%$ confidence intervals. Hypothesis 2, positing that the effect of deterrence is conditioned by subjective norms, thus appears to be largely corroborated.

Substantively, the possibility of being penalized tends to be an effective deterrent when subjective compliance norms are weak or even mild (median), but it becomes largely irrelevant as the strength of these norms reaches its maximum. This result should obviously be interpreted jointly with the fact that subjective norms themselves have a strong negative impact on the respondents' propensity for tax evasion (see Fig. 2 above). It appears that such norms somehow override the effect of penalties for evasion; those whose immediate reference groups create an environment favoring tax compliance do not need to be subjected to deterrence efforts as their propensity to evade taxes is low anyway. Those whose immediate reference groups do not offer such a setting will tend to engage in actions motivated by instrumental incentives, such as avoidance of punishment (Kroneberg et al. 2010; Matsueda et al. 2006). Hence the relevance of penalties for evasion as long as we consider tax behavior of those experiencing an environment marked by low subjective norms. Overall, the results point to the relevance of the claim that the perceived norms moderate the way people perceive tax system parameters and react to instrumental incentives posed by those parameters.

Last but not least, it must be mentioned that there is no clear moderating effect of descriptive norms on penalty, as the $95 \%$ confidence intervals for different levels of (descriptive) norms are overlapping significantly. The arguments (see above), positing that shaping of the perception of penalties 
is a process influenced predominantly by subjective norms (see also Doran 2009), thus seem to be largely confirmed. This also means that we did not find any effects resembling the core effect obtained by Wenzel (2004b); strong descriptive compliance norms do not appear to magnify the effect of deterrence. ${ }^{10}$ One of the potential factors behind the difference between our findings and those of Wenzel is a fundamental cultural disparity. His research was carried out in Australia, a setting with a tax gap lower than for virtually every country that we study (e.g., Raczkowski and Mróz 2018). In Australia, unlike in Central and Eastern Europe, the prevalent descriptive norms seem to work in the same direction as do legal sanctions and perhaps this is where the moderating (magnifying) effect found by Wenzel comes from. If so, further comparative research on these issues seems worth an effort.

Finally, models 3 and 4 present the results of the main model estimated separately for countries with flat tax rate (model 3) and progressive tax rate (model 4). The aim of disaggregating countries into two groups based on their tax system is to make sure that our results pointing to the moderating effect of norms on tax system parameters are not driven by the systemic features external to our factorial experiment. The results are generally in line with the main model, even if for countries with progressive tax systems the interaction terms miss the conventional statistical significance level $(p>0.05)$. The last is certainly a result of the subsample size falling below 5000 respondents (model 4), that is, a relatively unimpressive number given the complexity of our model.

\section{Robustness Checks}

We conduct robustness checks with respect to three types of potential threats to validity of our findings. Estimates for all of the tests are presented in the Appendix (Table 6). First, we add to our main model the interactions of both tax rate and penalty with personal norms (model 1 in Table 6). This does not change the estimates for our core variables to any significant degree. Moreover, the coefficients for the added interactions are statistically insignificant. We thus conclude that the absence of those interactions from our main model does not constitute a threat to the validity of our findings.

Second, we also estimate our models with the raw experimental tax rate, that is, the tax rate from the vignette question not divided by a respective country's actual tax rate (model 2 in Table 6). Perhaps somewhat surprisingly, the estimates support the conclusions drawn from our main model. The fact that the conclusions are robust to different operationalizations of tax rate is particularly reassuring for us.

\footnotetext{
${ }^{10}$ In a separate analysis, we excluded subjective norms in order for the estimated model to more closely resemble that of Wenzel (2004b). That analysis yielded results largely echoing those for our main model.
}

Finally, a potential serious reservation with respect to our analyses may point to endogeneity issues. Namely, there exists literature suggesting that people's subjective and descriptive norms are affected by their behavior. Even though the evidence we presented above is based on the experimental design, there is still a possibility that the declared behavior elicited in the vignette experiment affected subsequent responses to the questions referring to norms. This is because norms questions were asked after the vignette. Therefore, to make sure that our results are not spurious (artefactual), we have carried a further test that controls for the actual declared behavior (questions following those referring to norms). In the survey, respondents were asked "Has it ever happened that: you did not declare all of your income to the Tax Office?" and "You worked for cash-in-hand payment and DID NOT PAY tax on this income?". The available answers were Yes (1), No (2), Don't know (998) and Refuse (999). To ensure that the effect of norms on the hypothetical behavior reported in our survey experiment is not endogenous we have re-estimated the models controlling for both the aforementioned types of reported behavior (see model 3 in Table 6). Controlling for actual reported behavior does not affect the key explored relationships. Moreover, the explanatory effect of the behavior questions on our dependent variable (experimental behavior) is statistically insignificant (in the case of the 'cash-in-hand' question) or very weak and marginally insignificant (or significant at $p<0.1$ ), which suggests that our survey experiment successfully elicited the declared behavior conditional on the experiment's parameters.

\section{Conclusion}

In this study, we used data from a survey experiment on taxrelated attitudes of citizens of fourteen countries of Central and Eastern Europe to study the effects of tax system parameters - that is, tax rate and penalties for noncompliance — and various types of norms on the propensity for tax evasion. We followed in Wenzel's (2004b) and Coricelli et al.'s (2014) footsteps by proposing that policy outcomes depend on the social norms, broadly conceived. This way, we believe, we address major controversies regarding the impact of tax rates (Alm et al. 1992, 1995; Collins and Plumlee 1991; Friedland et al. 1978; Kirchler et al. 2008; Park and Hyun 2003) and deterrence (Doran 2009; Frey and Holler 1998; Kirchler et al. 2008; Posner 2000) on tax compliance, demonstrating that the impact of these tax system parameters is conditioned by the perceived social norms. Norms tend to act as heuristics facilitating people's response to the incentives posed by formal institutions (Gigerenzer and Todd 1999), including instrumental incentives posed by tax systems. They thus moderate the effects of both tax rate and penalties on the probability of respondents' underreporting an extra income paid in cash. Subjective norms - that is, norms of one's closest reference group — seem to be a particularly strong predictor 
of the propensity for tax evasion (Bobek et al. 2013). They also moderate the impact of deterrence, as penalty lowers respondents' propensity to underreport an income only among those who do not experience strong tax norms within their immediate reference group. We believe this finding may have far-reaching consequences for the understanding of tax-related behavior. It may also have policy implications as states may prefer to avoid an installation of high penalties for evasion and their unwanted long-term consequences (e.g., Frey and Holler 1998, p. 28) in contexts in which micro-level socialnorms-based barriers effectively prevent tax noncompliance.

Furthermore, descriptive norms are a clear moderating factor when it comes to the effect of tax rates. Tax rates have a (somewhat counterintuitive) negative impact on respondents' propensity for evasion in a situation in which descriptive norms are strong, that is, when a respondent is convinced that "most others" (society at large) are honest tax payers. We interpret it as a tendency to avoid a situation viewed as inequitable (Abraham et al. 2018; Erard and Feinstein 1994), that is, a situation where one unfairly benefits from relatively large honest contributions made by others. Low tax rates signal free-riding to be a negligible social offense, while high tax rates make it a significant social offense, which is further magnified by the fact that this behavior is not widespread (descriptive norms). In other words, it seems that high tax rates tend to increase the psychic costs of exploiting contributions of honest others and thus perceiving oneself as a "leech" (Hibbing and Alford 2004, p. 65), which, we believe, throws new light on previous counterintuitive findings similar to ours (e.g., Alm et al. 1995). At the same time, we encounter a certain degree of nuance, especially with the rather surprising finding that the positive effect of tax rate on the propensity for evasion when "most others" are believed not to be honest tax payers is weak and statistically insignificant (see above). This warrants further research on the impact of tax rates in diverse macro-settings. We also believe that our findings have important policy implications, suggesting that, as long as people believe that "most others" pay their fair share of tax, a reasonable increase in tax rates will not result in an actual increase of tax evasion.

The strength of our study and evidence presented stems from its unique design - an experimental setup embedded in a cross-national survey of representative samples in fourteen countries. This setup can be considered a weakness as well. All countries covered by the study are from one region- postCommunist Central-Eastern Europe. They form a distinct context for investigating tax behavior, which becomes evident when the persistent and endemic character of tax evasion in this region is noted. This raises questions as to the generalizability of mechanisms identified in our paper. On the other hand, all the investigated countries have institutional design that mirrors tax institutions in Western Europe and Northern America, thus the difference must be rooted in the cultural specificities that are partly a legacy of the Communist past, and partly a product of the post-Communist transition period (Torgler 2012; Williams and Horodnic 2015). Our study takes the advantage of the acceptability of tax evasion in post-Communist Europe, as the relative openness in which respondents express their views on tax noncompliance allows for a more thorough investigation of the direct and moderating effect of norms on tax compliance than in the more conservative contexts. Therefore, we believe that our study has tested mechanisms that would have been present yet more difficult to uncover in other settings. Of course, this conclusion does not preclude the necessity to replicate the analysis in other cultural contexts.

We also believe our study may have implications for future research on norm processes in other domains. We demonstrate that external context, formed by norms of one's closest reference group, may guarantee that one complies with tax law even without credible prospects of punishment. This reasoning may also apply to other types of behavior. For example, Blais and Achen (2019) propose a largely similar theory with respect to electoral participation, arguing that instrumental incentives increase the probability of casting a ballot only in the case of those who have not internalized a strong norm for voting (civic duty). Those who have developed such a norm tend to vote regardless of whether or not such incentives exist. Extensions of such findings to the context created by immediate reference groups, analogous to our effort focusing on tax compliance, would certainly deepen our understanding of the role of instrumental incentives and norms in shaping people's propensity to participate in elections.

Of course, our study demonstrates substantial heterogeneity with respect to the exact mechanisms whereby norms moderate the impact of different parameters of the tax system on citizens' propensity to evade taxes. Depending on the tax system parameter considered, subjective or descriptive norms might come into play as a moderating factor. On the other hand, one general conclusion from our study seems justified. Namely, norms tend to shape people's perception of tax system parameters and a profound understanding of the influence those parameters exert on citizens' propensity to pay taxes in an honest manner is possible only in the context of social norms, broadly conceived. More research is certainly needed to delve deeper into the mechanism in accordance with which tax system and social norms mutually affect each other's role in encouraging citizens to pay their fair share of taxes. The current analysis should contribute to that effort.

Acknowledgements An earlier draft of this paper was presented at the conference "The Shadow Economy, Tax Evasion and Informal Labor", Warsaw, 27-30 July 2017. We thank the participants of the conference for their comments there. We are also grateful to four anonymous reviewers from this journal for their observations on a later draft.

Funding This study was funded by the European Research Council (Grant Number 240830) and 'Idee dla Polski' by the Foundation for Polish Science. 


\section{Compliance with Ethical Standards}

Conflict of interest All authors declare that they have no conflict of interest.

Ethical Approval All procedures performed in studies involving human participants were in accordance with the ethical standards of the institutional and/or national research committee and with the 1964 Helsinki declaration and its later amendments or comparable ethical standards.

Human and Animal Rights This article does not contain any studies with animals performed by any of the authors.

Informed Consent Informed consent was obtained from all individual participants included in the study.
Open Access This article is licensed under a Creative Commons Attribution 4.0 International License, which permits use, sharing, adaptation, distribution and reproduction in any medium or format, as long as you give appropriate credit to the original author(s) and the source, provide a link to the Creative Commons licence, and indicate if changes were made. The images or other third party material in this article are included in the article's Creative Commons licence, unless indicated otherwise in a credit line to the material. If material is not included in the article's Creative Commons licence and your intended use is not permitted by statutory regulation or exceeds the permitted use, you will need to obtain permission directly from the copyright holder. To view a copy of this licence, visit http://creativecommons.org/licenses/by/4.0/.

\section{Appendix}

See Tables 4, 5, 6 and 7.

Table 4 Sample sizes and fieldwork dates

\begin{tabular}{|c|c|c|c|}
\hline 1. Bulgaria & & 8. Moldova & \\
\hline RR: & 0.49 & RR: & 0.51 \\
\hline N1: & 1732 & N1: & 1879 \\
\hline $\mathrm{N} 2:$ & 75 & $\mathrm{~N} 2$ : & 75 \\
\hline Fieldwork: & Nov 2013-Feb 2014 & Fieldwork: & Nov 2013-Aug 2014 \\
\hline 2. Croatia & & 9. Poland & \\
\hline RR: & 0.59 & RR: & 0.40 \\
\hline N1: & 1615 & N1: & 1540 \\
\hline $\mathrm{N} 2:$ & 75 & $\mathrm{~N} 2$ : & 75 \\
\hline Fieldwork: & Nov 2013-March 2014 & Fieldwork: & May 2013-Aug 2013 \\
\hline 3. Czech Republic & & 10. Romania & \\
\hline RR: & 0.44 & RR: & 0.47 \\
\hline N1: & 1502 & N1: & 1608 \\
\hline $\mathrm{N} 2$ : & 75 & $\mathrm{~N} 2$ : & 75 \\
\hline Fieldwork: & Nov 2013-Feb 2014 & Fieldwork: & Nov 2013-March 2014 \\
\hline 4. Estonia & & 11. Serbia & \\
\hline RR: & 0.42 & RR: & 0.52 \\
\hline N1: & 1501 & N1: & 1596 \\
\hline $\mathrm{N} 2$ : & 75 & $\mathrm{~N} 2$ : & 75 \\
\hline Fieldwork: & Dec 2013-July 2014 & Fieldwork: & Nov 2013-Feb 2014 \\
\hline 5. Hungary & & 12. Slovakia & \\
\hline RR: & 0.66 & RR: & .41 \\
\hline N1: & 1500 & N1: & 1505 \\
\hline $\mathrm{N} 2$ : & 75 & N2: & 75 \\
\hline Fieldwork: & Nov 2013-March 2014 & Fieldwork: & Feb 2014-April 2014 \\
\hline 6. Latvia & & 13. Slovenia & \\
\hline RR: & 0.44 & RR: & 0.52 \\
\hline N1: & 1521 & N1: & 1532 \\
\hline $\mathrm{N} 2$ : & 75 & $\mathrm{~N} 2$ : & 75 \\
\hline Fieldwork: & Jan 2014-March 2014 & Fieldwork: & Dec 2013-Feb 2014 \\
\hline 7. Lithuania & & 14. Ukraine & \\
\hline RR: & 0.51 & RR: & 0.40 \\
\hline N1: & 1596 & N1: & 1414 \\
\hline $\mathrm{N} 2:$ & 75 & N2: & 73 \\
\hline Fieldwork: & Nov 2013-March 2014 & Fieldwork: & Jan 2014-Aug 2014 \\
\hline
\end{tabular}


Table 5 Tax evasion vignette: distribution of factors and responses, $N=12,985$

\section{Percent}

Penalty (assigned randomly to respondents):

(no penalty mentioned)

If it is discovered that you have not declared this income to the Tax Office, you will have to pay the amount of tax you owe and an additional penalty of...

$50 \%$ of this amount

$100 \%$ of this amount

$150 \%$ of this amount

19.27

$200 \%$ of this amount

Tax rate (assigned randomly to respondents):

$10 \%$

$15 \%$

16.25

$20 \%$

16.89

$25 \%$

16.87

$30 \%$

16.90

$35 \%$

16.20

How likely it is that you will not declare this income to the Tax Office?

Not likely at all

Not very likely

24.97

Fairly likely

19.93

Very likely 
Table 6 Alternative model specifications

\begin{tabular}{|c|c|c|c|}
\hline \multirow[t]{2}{*}{ Variables } & (1) & (2) & (3) \\
\hline & $\begin{array}{l}\text { Interactions with personal } \\
\text { norms }\end{array}$ & $\begin{array}{l}\text { Tax rate as originally } \\
\text { coded }\end{array}$ & $\begin{array}{l}\text { Controlling for the } \\
\text { reported behavior }\end{array}$ \\
\hline \multirow[t]{2}{*}{ Tax rate } & $1.770^{* *}$ & 0.469 ** & $0.954 * *$ \\
\hline & $(0.895)$ & $(0.207)$ & $(0.485)$ \\
\hline \multirow[t]{2}{*}{ Penalty } & -0.351 & $-0.685^{* * *}$ & $-0.684 * * *$ \\
\hline & $(0.319)$ & $(0.180)$ & $(0.181)$ \\
\hline \multirow[t]{2}{*}{ Subjective } & $-1.435 * * *$ & $-1.328 * * *$ & $-1.296 * * *$ \\
\hline & $(0.301)$ & $(0.281)$ & $(0.290)$ \\
\hline \multirow[t]{2}{*}{ Subjective $\times$ tax } & $-1.138^{*}$ & $-0.621^{* *}$ & $-1.249 * *$ \\
\hline & $(0.601)$ & $(0.284)$ & $(0.592)$ \\
\hline \multirow[t]{2}{*}{ Subjective $\times$ penalty } & $0.683^{* * *}$ & $0.615^{* *}$ & $0.611^{* *}$ \\
\hline & $(0.264)$ & $(0.249)$ & $(0.250)$ \\
\hline \multirow[t]{2}{*}{ Descriptive } & 0.367 & 0.326 & 0.350 \\
\hline & $(0.424)$ & $(0.427)$ & $(0.440)$ \\
\hline \multirow[t]{2}{*}{ Descriptive $\times \operatorname{tax}$} & $-2.387 * *$ & $-1.015^{* *}$ & $-2.312 * *$ \\
\hline & $(0.933)$ & $(0.435)$ & $(0.935)$ \\
\hline \multirow[t]{2}{*}{ Descriptive $\times$ penalty } & 0.301 & 0.297 & 0.315 \\
\hline & $(0.372)$ & $(0.377)$ & $(0.381)$ \\
\hline \multirow[t]{2}{*}{ Personal } & -0.218 & $-0.854 * * *$ & $-0.838 * * *$ \\
\hline & $(0.419)$ & $(0.167)$ & $(0.167)$ \\
\hline \multirow[t]{2}{*}{ Personal $\times$ tax } & -1.125 & & \\
\hline & $(0.999)$ & & \\
\hline \multirow[t]{2}{*}{ Personal $\times$ penalty } & -0.488 & & \\
\hline & $(0.405)$ & & \\
\hline \multirow[t]{2}{*}{ Retributive } & 0.0366 & 0.0406 & 0.027 \\
\hline & $(0.146)$ & $(0.145)$ & $(0.147)$ \\
\hline \multicolumn{4}{|c|}{ Has it ever happened that: you did not declare all of your income to the Tax Office? } \\
\hline \multicolumn{4}{|l|}{ Ref. cat: Yes } \\
\hline \multirow[t]{2}{*}{ No } & & & $-0.212 *$ \\
\hline & & & $(0.117)$ \\
\hline \multirow[t]{2}{*}{ Don't know } & & & -0.096 \\
\hline & & & $(0.315)$ \\
\hline \multirow[t]{2}{*}{ Refusal } & & & 0.0135 \\
\hline & & & $(0.292)$ \\
\hline \multicolumn{4}{|c|}{ Has it ever happened that: You worked for cash-in-hand payment and DID NOT PAY tax on this income? } \\
\hline \multicolumn{4}{|l|}{ Ref. cat: Yes } \\
\hline \multirow[t]{2}{*}{ No } & & & 0.004 \\
\hline & & & $(0.113)$ \\
\hline \multirow[t]{2}{*}{ Don't know } & & & 0.328 \\
\hline & & & $(0.424)$ \\
\hline Refusal & & & $-0.513 *$ \\
\hline & & & $(0.282)$ \\
\hline /cut1 & $-2.476 * * *$ & $-2.915^{* * *}$ & $-3.032 * * *$ \\
\hline & $(0.375)$ & $(0.271)$ & $(0.286)$ \\
\hline /cut2 & $-1.072 * * *$ & $-1.511 * * *$ & $-1.625 * * *$ \\
\hline & $(0.373)$ & $(0.267)$ & $(0.283)$ \\
\hline /cut3 & 0.234 & -0.204 & -0.316 \\
\hline & $(0.372)$ & $(0.265)$ & $(0.280)$ \\
\hline Log pseudolikelihood & $-15,221.406$ & $-15,218.936$ & $-15,206.757$ \\
\hline Observations & 11,861 & 11,861 & 11,861 \\
\hline
\end{tabular}

Robust standard errors in parentheses. $* * * p<0.01, * * p<0.05, * p<0.1$

All models controlled for age, sex, education (degree), whether respondent is employed. All models control include country fixed-effects 
Table 7 Distribution characteristics of independent and control variables

\begin{tabular}{llllll}
\hline Variable & $\mathrm{N}$ & \multicolumn{3}{l}{ Distribution characteristics } \\
\cline { 3 - 6 } & & Mean & SD & Min & Max \\
\hline Tax ratio & 14,436 & 0.26 & 0.19 & 0 & 1 \\
Personal norms & 14,436 & 0.78 & 0.20 & 0 & 1 \\
Subjective norms & 14,199 & 0.51 & 0.35 & 0 & 1 \\
Descriptive norms & 13,214 & 0.37 & 0.24 & 0 & 1 \\
Retributive capacity & 14,411 & 0.35 & 0.25 & 0 & 1 \\
Age & 14,436 & 49.71 & 15.95 & 15.61 & 93.96 \\
& & 0 & 1 & Min & Max \\
Penalty & 14,436 & $19.51 \%$ & $80.49 \%$ & 0 & 1 \\
Gender & 14,436 & $44.26 \%$ & $55.74 \%$ & 0 & 1 \\
Degree & 14,436 & $76.68 \%$ & $23.32 \%$ & 0 & 1 \\
Working & 14,335 & $38.98 \%$ & $61.02 \%$ & 0 & 1 \\
\hline
\end{tabular}

Survey sample and fieldwork information. "Public Goods through Private Eyes" survey (Letki 2015), full-scale faceto-face on representative national samples, clustered at the level of PSUs (LAU or equivalent; in large cities-city district), N1 (individuals) $=22,041 ; \mathrm{N} 2(\mathrm{PSUs})=1048 ; \mathrm{N} 3$ (countries) $=14$.

\section{References}

Abraham, M., Lorek, K., Richter, F., \& Wrede, M. (2018). Breaking the norms: When is evading inheritance taxes socially acceptable? European Journal of Political Economy, 52, 85-102.

Ai, C., \& Norton, E. C. (2003). Interaction terms in logit and probit models. Economics Letters, 80(1), 123-129.

Alesina, A., \& Angeletos, G. M. (2005). Fairness and redistribution. American Economic Review, 95(4), 960-980.

Allingham, M. G., \& Sandmo, A. (1972). Income tax evasion: A theoretical analysis. Journal of Public Economics, 1(3-4), $323-338$

Alm, J. (2012). Measuring, explaining, and controlling tax evasion: lessons from theory, experiments, and field studies. International Tax and Public Finance, 19(1), 54-77.

Alm, J., McClelland, G. H., \& Schulze, W. D. (1992). Why do people pay taxes? Journal of Public Economics, 48(1), 21-38.

Alm, J., Sanchez, I., \& De Juan, A. (1995). Economic and noneconomic factors in tax compliance. Kyklos, 48(1), 1-18.

Bicchieri, C., \& Xiao, E. (2009). Do the right thing: But only if others do so. Journal of Behavioral Decision Making, 22(2), 191-208.

Blais, A., \& Achen, C. H. (2019). Civic duty and voter turnout. Political Behavior, 41(2), 473-497.

Bobek, D. D., Hageman, A. M., \& Kelliher, C. F. (2013). Analyzing the role of social norms in tax compliance behavior. Journal of Business Ethics, 115(3), 451-468.

Bobek, D. D., Roberts, R. W., \& Sweeney, J. T. (2007). The social norms of tax compliance: Evidence from Australia, Singapore, and the United States. Journal of Business Ethics, 74(1), 49-64.
Brizi, A., Giacomantonio, M., Schumpe, B. M., \& Mannetti, L. (2015). Intention to pay taxes or to avoid them: The impact of social value orientation. Journal of Economic Psychology, 50(3), 22-31.

Clotfelter, C. T. (1983). Tax evasion and tax rates: An analysis of individual returns. Review of Economics and Statistics, 65(3), 363-373.

Collins, J. H., \& Plumlee, R. D. (1991). The taxpayer's labor and reporting decision: The effect of audit schemes. Accounting Review, 66(3), 559-576.

Coricelli, G., Rusconi, E., \& Villeval, M. C. (2014). Tax evasion and emotions: An empirical test of re-integrative shaming theory. Journal of Economic Psychology, 40, 49-61.

Doran, M. (2009). The penalties and tax compliance. Harvard Journal of Legislation, 46, 111-161.

Erard, B., \& Feinstein, J. S. (1994). Honesty and evasion in the tax compliance game. The RAND Journal of Economics, 25(1), 1-19.

Ferrer-i-Carbonell, A., \& Gërxhani, K. (2016). Tax evasion and wellbeing: A study of the social and institutional context in Central and Eastern Europe. European Journal of Political Economy, 45, 149-159.

Frey, B. S. (1997). Not just for the money: An economic theory of personal motivation. Cheltenham, UK-Brookfield, US: Edward Elgar Publishing.

Frey, B. S., \& Holler, M. J. (1998). Tax compliance policy reconsidered. Homo Oeconomicus, 15(1), 27-44.

Friedland, N., Maital, S., \& Rutenberg, A. (1978). A simulation study of income tax evasion. Journal of Public Economics, 10(1), $107-116$.

Gërxhani, K. (2004a). Tax evasion in transition: Outcome of an institutional clash? Testing Feige's conjecture in Albania. European Economic Review, 48(4), 729-745.

Gërxhani, K. (2004b). The informal sector in developed and less developed countries: a literature survey. Public Choice, 120(3-4), 267-300.

Gigerenzer, G., \& Todd, P. M. (1999). Fast and frugal heuristics: The adaptive toolbox. In G. Gigerenzer \& P. M. Todd (Eds.), Simple heuristics that make us smart (pp. 3-34). Oxford: Oxford University Press.

Hibbing, J. R., \& Alford, J. R. (2004). Accepting authoritative decisions: Humans as wary cooperators. American Journal of Political Science, 48(1), 62-76.

King, G., Tomz, M., \& Wittenberg, J. (2000). Making the most of statistical analyses: Improving interpretation and presentation. American Journal of Political Science, 44(2), 347-361.

Kirchler, E., Hoelzl, E., \& Wahl, I. (2008). Enforced versus voluntary tax compliance: The "slippery slope" framework. Journal of Economic Psychology, 29(2), 210-225.

Kroneberg, C., Heintze, I., \& Mehlkop, G. (2010). The interplay of moral norms and instrumental incentives in crime causation. Criminology, 48(1), 259-294.

Letki, N. (2015). Public Goods through Private Eyes. Dataset. Warsaw: University of Warsaw.

Matsueda, R. L., Kreager, D. A., \& Huizinga, D. (2006). Deterring delinquents: A rational choice model of theft and violence. American Sociological Review, 71(1), 95-122.

Mehlkop, G., \& Graeff, P. (2010). Modelling a rational choice theory of criminal action: Subjective expected utilities, norms, and interactions. Rationality and Society, 22(2), 189-222.

Onu, D., \& Oats, L. (2015). The role of social norms in tax compliance: Theoretical overview and practical implications. Journal of Tax Administration, 1(1), 113-137.

Park, C. G., \& Hyun, J. K. (2003). Examining the determinants of tax compliance by experimental data: A case of Korea. Journal of Policy Modeling, 25(8), 673-684.

Pickhardt, M., \& Prinz, A. (2014). Behavioral dynamics of tax evasion-a survey. Journal of Economic Psychology, 40, 1-19. 
Posner, E. A. (2000). Law and social norms: The case of tax compliance. Virginia Law Review, 86, 1781-1819.

Raczkowski, K., \& Mróz, B. (2018). Tax gap in the global economy. Journal of Money Laundering Control, 21(4), 567-583.

Rossi, P. H. (1979). Vignette analysis: Uncovering the normative structure of complex judgments. In R. K. Merton, J. S. Coleman, \& P. H. Rossi (Eds.), Qualitative and quantitative social research (pp. 176-186). New York: Free Press.

Sigala, M., Burgoyne, C. B., \& Webley, P. (1999). Tax communication and social influence: Evidence from a British sample. Journal of Community and Applied Social Psychology, 9(3), 237-241.

Slemrod, J. (1985). An empirical test for tax evasion. Review of Economics and Statistics, 67(2), 232-238.

Smith, V. L. (2003). Constructivist and ecological rationality in economics. American Economic Review, 93(3), 465-508.

Thurman, Q. C. (1989). General prevention of tax evasion: A factorial survey approach. Journal of Quantitative Criminology, 5(2), 127-146.

Torgler, B. (2012). Tax morale, Eastern Europe and European enlargement. Communist and Post-Communist Studies, 45(1), 11-25.

Ugrin, J. C., \& Odom, M. D. (2010). Exploring Sarbanes-Oxley's effect on attitudes, perceptions of norms, and intentions to commit financial statement fraud from a general deterrence perspective. Journal of Accounting and Public Policy, 29(5), 439-458.

Van Dijk, E., Mulder, L. B., \& De Kwaadsteniet, E. W. (2014). For the common good? The use of sanctions in social dilemmas. In
P. A. Van Lange, B. Rockenbach, \& T. Yamagishi (Eds.), Reward and punishment in social dilemmas (pp. 70-84). Oxford: Oxford University Press.

Wallander, L. (2009). 25 years of factorial surveys in sociology: A review. Social Science Research, 38(3), 505-520.

Wenzel, M. (2002). The impact of outcome orientation and justice concerns on tax compliance: The role of taxpayers' identity. Journal of Applied Psychology, 87(4), 629-645.

Wenzel, M. (2004a). An analysis of norm processes in tax compliance. Journal of Economic Psychology, 25(2), 213-228.

Wenzel, M. (2004b). The social side of sanctions: Personal and social norms as moderators of deterrence. Law and Human Behavior, $28(5), 547-567$.

Wenzel, M. (2005). Motivation or rationalisation? Causal relations between ethics, norms and tax compliance. Journal of Economic Psychology, 26(4), 491-508.

Williams, C. C., \& Horodnic, I. A. (2015). Evaluating the prevalence of the undeclared economy in Central and Eastern Europe: An institutional asymmetry perspective. European Journal of Industrial Relations, 21(4), 389-406.

Publisher's Note Springer Nature remains neutral with regard to jurisdictional claims in published maps and institutional affiliations. 